\title{
GAMBARAN FAKTOR-FAKTOR IBU MENGIKUTI KELAS IBU HAMIL DI WILAYAH KERJA PUSKESMAS TEMPURAN KABUPATEN MAGELANG TAHUN 2013
}

\author{
Nova Wijanarko', Siti Fadhilah ${ }^{2}$, Dusi Catur Susiwati ${ }^{3}$ \\ 'Dinas Kesehatan DIY, ${ }^{2}$ STIKes Guna Bangsa Yogyakarta, ${ }^{3}$ STIKes Guna Bangsa Yogyakarta
}

\begin{abstract}
Background : The maternal mortality rate (MMR) and infant mortality rate (IMR) is an indicator of success in the development of the health sector. One of the new breakthroughs in the health section of the family in an effort to lower the maternal mortality rate is to establish Pregnancy Class. Pregnancy class is a means to learn together about the health of pregnant women, in the form of face-to-face in a group that aims to increase knowledge, change attitudes and behaviors in order to understand the mother's pregnancy, the body changes and complaints during pregnancy, prenatal care, delivery, postnatal care, KB postpartum, newborn care, myths, beliefs, local customs, infectious diseases and birth certificates.
\end{abstract}

Objective : Knowing description of the factors pregnant mothers attend classes.

Method : This study is the descriptive type, using cross-sectional approach. The sampling technique used was simple random sampling with a sample size in this study was 57 respondents.

Results: Most of the mothers knowledge level of pregnant women who attend classes are good that as many as 45 respondents $(78.9 \%)$. Most of the mothers who attend classes pregnant women have high levels of basic education (elementary and secondary) as many as 44 respondents $(77.2 \%)$. Most have the attitude agrees with the class of pregnant women as many as 46 respondents (80.7\%). Most of the husband to provide support to mothers who attend classes pregnant women as many as 44 respondents $(77.2 \%)$.

Conclutions : The level of knowledge of mothers who attend classes either pregnant women, the level of basic education, has agreed attitudes toward classroom activities pregnant women, and the husband's mother gave support to pregnant mothers to attend classes.

Keywords : Knowledge, Education, Attitude, Support Husband, Pregnancy Class

\section{PENDAHULUAN}

Angka kematian ibu (AKI) dan angka kematian bayi (AKB) merupakan indikator keberhasilan pembangunan pada sektor kesehatan. Angka Kematian lbu mengacu pada jumlah kematian ibu yang terkait dengan masa kehamilan, persalinan, dan nifas (Depkes RI, 2009). Sekitar 800 wanita meninggal setiap harinya dengan penyebab yang berkaitan dengan kehamilan dan persalinan. Hampir seluruh kematian maternal terjadi di negara berkembang dengan tingkat mortalitas yang lebih tinggi di area pedesaan dan komunitas miskin dan berpendidikan rendah (WHO, 2012).

Kematian Ibu di Jawa Tengah pada tahun 2012, berdasarkan laporan dari kabupaten/ kota sebesar 116,34/100.000 kelahiran hidup, mengalami peningkatan jika dibandingkan dengan AKI pada tahun 2011 sebesar 116,01/100.000 kelahiran hidup, dan untuk menurunkan AKI harus mensinergiskan beberapa program yang terkait mulai dari sejak saat Ibu hamil, melahirkan, bayi, balita, remaja, Pasangan Usia Subur (PUS) sampai Usia lanjut. Salah satu terobosan baru di seksi kesehatan keluarga dalam upaya menurunkan Angka Kematian lbu adalah dengan membentuk Kelas Ibu Hamil (Dinkes Jateng, 2012).

Kelas Ibu Hamil merupakan sarana untuk belajar bersama tentang kesehatan bagi ibu hamil, dalam bentuk tatap muka dalam kelompok yang bertujuan meningkatkan pengetahuan, merubah sikap dan perilaku ibu agar memahami tentang Kehamilan, perubahan tubuh dan keluhan selama kehamilan, perawatan kehamilan, persalinan, perawatan Nifas, KB pasca persalinan, 
perawatan bayi baru lahir, mitos, kepercayaan, adat istiadat setempat, penyakit menular dan akte kelahiran. Di kelas ini ibu hamil akan belajar bersama, diskusi dan tukar pengalaman tentang kesehatan Ibu dan anak (KIA) secara menyeluruh dan sistimatis serta dapat dilaksanakan secara terjadwal dan berkesinambungan (Kemenkes RI, 2011).

Salah satu wilayah yang telah melaksanakan program kelas ibu hamil adalah wilayah Kecamatan Tempuran. Puskesmas Tempuran merupakan pemegang tanggung jawab kesehatan masyarakat di wilayah Kecamatan Tempuran dengan 15 desa binaan. Pelaksanaan kelas ibu hamil selama ini dilakukan pada desa-desa dengan luas wilayah yang besar, sedangkan pada desadesa kecil dengan jumlah ibu hamil sedikit digabungkan dalam satu kelompok salah satunya adalah Desa Kalisari, Desa Girirejo dan Desa Tanggulrejo.

Jumlah ibu hamil sampai bulan Agustus 2013 di Desa Kalisari, Desa Girirejo dan Desa Tanggulrejo sebanyak 134 ibu hamil dan sebanyak 57 ibu hamil aktif mengikuti kegiatan kelas ibu hamil. Berdasarkan survey pendahuluan yang dilakukan peneliti, 3 ibu hamil menyatakan mengikuti kelas ibu hamil karena diberitahu petugas kesehatan, 1 ibu hamil menyatakan mengikuti kelas ibu hamil karena dorongan dari suami, 1 ibu hamil menyatakan karena sudah berusia 36 tahun dan merupakan kehamilan yang ke 3 dan 1 ibu hamil mengikuti kelas ibu hamil karena mengikuti ajakan temannya. Hasil survey juga menunjukkan 3 ibu hamil yang aktif mengikuti kelas ibu hamil, 2 diantaranya menjalani proses persalinan dengan baik, dan pada 3 ibu hamil yang tidak aktif mengikuti kelas ibu hamil, 2 ibu hamil diantaranya mengalami anemia karena kurang mengetahui kebutuhan gizi ibu selama masa kehamilan.

Berdasarkan studi pendahuluan diatas maka penulis tertarik untuk melakukan penelitian tentang gambaran faktor-faktor ibu mengikuti kelas ibu hamil di wilayah kerja Puskesmas Tempuran Kabupaten Magelang tahun 2013.

\section{PEMBAHASAN}

1. Tingkat pengetahuan ibu yang mengikuti kelas ibu hamil tentang kelas ibu hamil di wilayah kerja Puskesmas Tempuran Kabupaten Magelang tahun 2013

Tabel 1 Distribusi Frekuensi Tingkat Pengetahuan Ibu yang Mengikuti Kelas Ibu Hamil tentang Kelas Ibu Hamil di Wilayah Kerja Puskesmas Tempuran Kabupaten Magelang Tahun 2013

\begin{tabular}{llll}
\hline No & Kategori & Frekuensi & Persentase (\%) \\
\hline 1 & Baik & 45 & 78,9 \\
2 & Cukup & 12 & 21,1 \\
3 & Kurang & 0 & 0 \\
\hline & JUMLAH & 57 & 100 \\
\hline
\end{tabular}

Sumber : Data Primer, 2013

Tingkat pengetahuan ibu yang mengikuti kelas ibu hamil tentang kelas ibu hamil dari 57 responden terbanyak ada pada kategori baik yaitu $45 \quad(78,9 \%)$ responden dan sedikit adalah kategori cukup yaitu $12(21,1 \%)$ responden. Hal ini menunjukkan bahwa tingkat pengetahuan ibu tentang kelas ibu hamil sudah baik, hal ini ditunjukkan dengan sebagian besar ibu hamil yang menjawab benar pada setiap pertanyaan yang ada dalam lembar kuesioner.

Hasil penelitian ini sejalan dengan hasil penelitian yang dilakukan Mulyati (2011) di desa Gunungsari Kecamatan Bansari Kabupaten Temanggung Tahun 2011 yang menyatakan bahwa tingkat pengetahuan responden tentang kelas ibu hamil yang menempati tingkat pengetahuan baik mempunyai prosentase dari 28 responden yaitu $89,3 \% \quad(25$ responden).
Hal ini sesuai dengan pendapat Notoatmodjo (2010a) yaitu bahwa bila seseorang mampu menjawab pertanyaanpertanyaan mengenai bidang tertentu dengan lancar, baik lisan maupun tulisan, maka dia dapat dikatakan mengetahui bidang tersebut dan dengan pengetahuan yang baik maka perilaku kesehatan seseorang juga akan baik, hal ini juga ditunjukkan dengan tingkat pengetahuan ibu hamil yang baik tentang kelas ibu hamil sehingga mempengaruhi ibu untuk ikut kegiatan kelas ibu hamil.

Pengetahuan adalah hasil tahu dan ini terjadi setelah orang melakukan pengindraan terhadap suatu objek tertentu. Sebagian besar penginderaan manusia diperoleh melalui mata dan telinga. Pengetahuan kognitif merupakan domain yang sangat penting dalam membentuk tindakan seseorang (overt behavior) (Notoatmodjo, 2010a). 
Menurut Wawan dan Dewi (2010) berbagai cara penerapan pengetahuan baik dalam menghimpun berbagai macam gangguan maupun cara-cara mengatasinya tersebut merupakan pencerminan dari berbagai bentuk perilaku. Pengetahuan itu sendiri dipengaruhi oleh faktor pendidikan formal. Pengetahuan sangat erat hubungannya dengan pendidikan, dimana diharapkan bahwa dengan pendidikan yang tinggi maka orang tersebut akan semakin luas pula pengetahuannya, sehingga dengan pengetahuan ibu hamil yang baik tentang kelas ibu hamil dapat mempengaruhi perilaku ibu hamil dalam mengikuti kegiatan kelas ibu hamil

2. Tingkat pendidikan ibu yang mengikuti kelas ibu hamil di wilayah kerja Puskesmas Tempuran Kabupaten Magelang tahun 2013

Tabel 2 Distribusi Frekuensi Tingkat Pendidikan Ibu yang Mengikuti Kelas Ibu Hamil di Wilayah Kerja Puskesmas Tempuran Kabupaten Magelang tahun 2013

\begin{tabular}{llll}
\hline No & Kategori & Frekuensi & Persentase (\%) \\
\hline 1 & Dasar & 44 & 77,2 \\
2 & Menengah & 13 & 22,8 \\
3 & Tinggi & 0 & 0 \\
\hline & JUMLAH & 57 & 100 \\
\hline
\end{tabular}

Sumber : Data Primer, 2013

Tingkat pendidikan ibu yang mengikuti kelas ibu hamil dari 57 responden terbanyak ada pada kategori pendidikan dasar yaitu $44(77,2 \%)$ responden dan paling sedikit pada kategori tingkat pendidikan menengah yaitu $13(22,8 \%)$ responden.

Hasil penelitian ini sejalan dengan hasil penelitian Mulyati (2011) di desa Gunungsari Kecamatan Bansari Kabupaten Temanggung Tahun 2011 dari 28 responden dengan hasil tingkat pendidikan ibu hamil adalah tingkat pendidikan dasar yaitu sebanyak 26 $(92,9 \%)$ ibu.

Pendidikan dasar menurut Tirtarahardja dan Sulo (2005) adalah jenjang pendidikan awal selama 9 tahun pertama masa sekolah anak-anak yang melandasi jenjang pendidikan menengah. Di akhir masa pendidikan dasar selama 6 tahun pertama (SD/MI), para siswa harus mengikuti dan lulus dari Ujian Nasional (UN) untuk dapat melanjutkan pendidikannya ke tingkat selanjutnya (SMP/MTs) dengan lama pendidikan 3 tahun.

Pendidikan menurut Notoatmodjo (2010) adalah segala upaya yang direncanakan untuk mempengaruhi orang lain baik individu, kelompok atau masyarakat sehingga mereka melakukan apa yang diharapkan oleh pelaku pendidikan. Pendidikan diperlukan untuk mendapatkan informasi (Wawan dan Dewi, 2010).

Pendidikan yang rendah biasanya sulit untuk menerima informasi, hal ini sesuai pendapat Mubarak (2006) bahwa makin tinggi pendidikan seseorang makin mudah menerima informasi sehingga makin banyak pula pengetahuan yang dimiliki. Sebaliknya pendidikan yang kurang akan menghambat perkembangan sikap seseorang tehadap nilai-nilai yang baru diperkenalkan.

Selain pendidikan formal, pendidikan non formal untuk meningkatkan pengetahuan ibu hamil dapat dilakukan dengan cara ibu mengikuti kelas ibu hamil, sehingga melalui kelas ibu hamil dapat meningkatkan pengetahuan ibu tentang kehamilan dan persalinan sehingga dapat memperlancar proses persalinan.

3. Sikap ibu yang mengikuti kelas ibu hamil di wilayah kerja Puskesmas Tempuran Kabupaten Magelang tahun 2013

Tabel 3 Distribusi Frekuensi Sikap lbu yang Mengikuti Kelas Ibu Hamil di Wilayah Kerja Puskesmas Tempuran Kabupaten Magelang Tahun 2013

\begin{tabular}{llll}
\hline No & Kategori & Frekuensi & Persentase (\%) \\
\hline 1 & Setuju & 46 & 80,7 \\
2 & Tidak Setuju & 11 & 19,3 \\
\hline & JUMLAH & 77 & 100 \\
\hline
\end{tabular}

Sumber : Data Primer, 2013 
Sikap ibu yang mengikuti kelas ibu hamil dari 57 responden terbanyak ada pada kategori setuju yaitu $46(80,7 \%)$ responden dan kategori tidak setuju yaitu $11(19,3 \%)$ responden. Hasil penelitian ini sejalan dengan hasil penelitian Mulyati (2011) di desa Gunungsari Kecamatan Bansari Kabupaten Temanggung Tahun 2011 da yang menyatakan bahwa dari 28 responden sebanyak $25 \quad(89,3 \%)$ responden memiliki sikap yang baik terhadap pelaksanaan kelas ibu hamil, sehingga ada hubungan antara sikap ibu dengan keikutsertaan ibu dalam kelas ibu. Sikap yang mendukung dapat menyebabkan ibu mengikuti kelas ibu hamil

Menurut Notoatmodjo (2010a) sikap menggambarkan suka atau tidak suka seseorang terhadap objek. Pengetahuan dan sikap diperoleh dari pengalaman sendiri atau pengalaman orang lain dan salah satu bentuk sikap terhadap kesehatan pada ibu hamil adalah sikap terhadap risiko yang bisa saja terjadi selama kehamilan.

4. Dukungan suami ibu yang mengikuti kelas ibu hamil di wilayah kerja Puskesmas Tempuran Kabupaten Magelang tahun 2013

Tabel 4 Distribusi Frekuensi Dukungan Suami lbu yang Mengikuti Kelas Ibu Hamil di Wilayah Kerja Puskesmas Tempuran Kabupaten Magelang Tahun 2013

\begin{tabular}{llll}
\hline No & Kategori & Frekuensi & Persentase (\%) \\
\hline 1 & Mendukung & 44 & 77,2 \\
2 & Tidak Mendukung & 13 & 22,8 \\
\hline & JUMLAH & 77 & 100 \\
\hline
\end{tabular}

Sumber : Data Primer, 2013

Dukungan suami ibu yang mengikuti kelas ibu hamil dari 57 responden terbanyak ada pada kategori mendukung yaitu $44(77,2 \%)$ responden dan sedikit adalah tidak mendukung yaitu $13(22,8 \%)$ responden.

Hasil penelitian ini sejalan dengan hasil penelitian Mulyati (2011) di desa Gunungsari Kecamatan Bansari Kabupaten Temanggung Tahun 2011 dari 28 responden sebanyak $23(82,1 \%)$ ibu hamil menyatakan mendapat dukungan dari suami untuk mengikuti pelaksanaan kelas ibu hamil dan sebanyak 5 (17,9\%) ibu hamil menyatakan tidak mendapatkan dukungan dari suami.

Menurut Sarafino (2006) dukungan adalah suatu bentuk kenyamanan, perhatian, penghargaan, ataupun bantuan yang diterima individu dari orang yang berarti, baik secara perorangan maupun kelompok, sedangkan menurut pendapat Rukiyah dan Yulianti (2009) orang yang paling penting bagi seorang ibu hamil adalah suami. Ada 4 jenis dukungan yang dapat diberikan suami sebagai calon ayah bagi anaknya antara lain dukungan emosi yaitu suami sepenuhnya memberi dukungan secara psikologis dengan menunjukkan kepedulian dan perhatian kepada kehamilannya serta peka terhadap kebutuhan dan perubahan emosi ibu hamil. Dukungan instrumental yaitu dukungan suami yang diberikan untuk memenuhi kebutuhan fisik ibu hamil dengan bantuan keluarga lainnya, dukungan informasional yaitu dukungan suami dalam memberikan informasi yang diperoleh mengenai kehamilan dan dukungan penilaian yaitu memberikan keputusan yang tepat untuk perawatan kehamilan istrinya.

Dukungan suami dapat ditunjukkan dengan mengantar ibu mengikuti kelas ibu hamil. Dukungan tersebut dapat merupakan bentuk dukungan instrumental yang menurut Sarafino (2006) merupakan penyediaan materi yang dapat memberikan pertolongan langsung seperti pinjaman uang, pemberian barang, makanan serta pelayanan. Bentuk dukungan ini dapat mengurangi stress karena individu dapat langsung memecahkan masalahnya yang berhubungan dengan materi. Dukungan instrumental sangat diperlukan terutama dalam mengatasi masalah dengan lebih mudah.

Dukungan lain dapat diberikan suami dengan memberikan semangat kepada ibu untuk terus mengikuti kelas ibu hamil. Hal ini merupakan dukungan emosional, yang menurut Sarafino (2006) membuat individu memiliki perasaan nyaman, yakin, diperdulikan dan dicintai oleh sumber dukungan sosial sehingga individu dapat menghadapi masalah dengan lebih baik. Dukungan ini sangat penting dalam 
menghadapi keadaan yang dianggap tidak dapat dikontrol.

Dukungan informasional berupa memberikan informasi kepada ibu tentang masalah kehamilan dan persalinan dapat dilakukan suami dengan cara ikut serta mendampingi ibu dalam kegiatan kelas ibu hamil, yang menurut Sarafino (2006) dukungan ini melibatkan pemberian informasi, saran atau umpan balik tentang situasi dan kondisi individu, Jenis informasi seperti ini dapat menolong individu untuk mengenali dan mengatasi masalah dengan lebih mudah.

Bentuk dukungan harga diri dapat diberikan suami kepada ibu hamil dengan cara memberikan pujian kepada ibu yang menurut Sarafino (2006) berupa penghargaan positif pada individu, pemberian semangat, persetujuan pada pendapat individu, perbandingan yang positif dengan individu lain. Bentuk dukungan ini membantu individu dalam membangun harga diri dan kompetensi.

\section{KESIMPULAN}

Berdasarkan hasil penelitian gambaran faktorfaktor ibu mengikuti kelas ibu hamil di wilayah kerja Puskesmas Tempuran Kabupaten Magelang tahun 2013 maka peneliti menyimpulkan :

1. Tingkat pengetahuan ibu yang mengikuti kelas ibu hamil dari 57 responden terbanyak adalah kategori baik yaitu 45 $(78,9 \%)$ responden.

2. Tingkat pendidikan yang mengikuti kelas ibu hamil dari 57 responden terbanyak tingkat pendidikan dasar (SD dan SMP) yaitu 44 responden $(77,2 \%)$ responden.

3. Sikap ibu yang mengikuti kelas ibu hamil dari 57 responden terbanyak adalah memiliki sikap setuju dengan adanya kelas ibu hamil sebanyak $46 \quad(80,7 \%)$ responden.

4. Dukungan suami ibu yang mengikuti kelas ibu hamil dari 57 responden terbanyak adalah ikut memberikan kontribusi ibu mengikuti kelas ibu hamil sebanyak 44 $(77,2 \%)$ responden.

\section{SARAN}

Setelah peneliti melakukan penelitian tentang faktor-faktor ibu mengikuti kelas ibu hamil di wilayah kerja Puskesmas Tempuran Kabupaten Magelang tahun 2013, peneliti memiliki saran sebagai berikut :
1. Bagi Bidan

Membina kerja sama lintas sektoral dengan kader, Tim Penggerak PKK, tokoh masyarakat dan tokoh agama sebagai perpanjangan tangan bidan di desa untuk dapat terus membantu dalam sosialisasi pelaksanaan kelas ibu hamil, dan dapat terus memberikan dukungan kepada ibu untuk mengikuti kelas ibu hamil.

2. Bagi lbu Hamil

Ibu hamil lebih meningkatkan pengetahuan tentang manfaat kelas ibu hamil dan dapat memotivasi diri sendiri untuk terus mengikuti kegiatan kelas ibu hamil untuk menunjang keselamatan dan kesehatan ibu serta janin dalam kandungan dengan mengikuti kegiatankegiatan yang berhubungan dengan kesehatan seperti aktif dalam kegiatan kelas ibu hamil maupun posyandu.

3. Bagi Penelitian Selanjutnya

Diharapkan untuk dapat memperluas jumlah responden dengan cara memperluas wilayah penelitian sehingga hasil penelitian yang dicapai lebih baik.

4. Bagi Program

Diharapkan untuk lebih meningkatkan kinerja program kelas ibu hamil dengan metode-metode baru yang lebih dimengerti ibu hamil.

\section{DAFTAR PUSTAKA}

Budiarto, E. (2002). Biostatistika untuk kedokteran dan Kesehatan Masyarakat. Jakarta : EGC.

Depkes RI. (2009a). Pegangan Fasilitator Kelas Ibu Hamil. Jakarta : Departemen Kesehatan RI.

Depkes RI. (2009b). Pedoman Pelaksanaan Kelas Ibu Hamil. Jakarta : Departemen Kesehatan RI

Depkes RI. (2009c). Pelatihan Kelas Ibu Hamil. Jakarta : Departemen Kesehatan RI.

Depkes RI. (2009d). Pedoman Umum Manajemen Kelas lbu Hamil. Jakarta : Departemen Kesehatan RI.

Depkes RI. (2009e). Profil Kesehatan Indonesia 2008. Jakarta : Depkes RI.

Dinkes Jateng. (2012). Profil kesehatan jawa tengah 2011. Semarang : Dinkes Jateng.

Hardini. (2011). Gambaran Pelaksanaan Kelas ibu Hamil oleh Bidan di Wilayah Kerja 
Puskesmas Tepusen Kabupaten Temanggung Tahun 2011. Magelang : KTI Politeknik Kemenkes RI Magelang

Hidayat. (2010). Metode Penelitian Kebidanan dan Teknik Analisis Data.Jakarta : Salemba Medika.

Kemenkes RI. (2011). Pedoman Pelaksanaan Kelas Ibu Hamil. Jakarta : Kemenkes RI.

Maryunani dan Yulianingsih. (2009). Asuhan Kegawatdaruratan dalam Kebidanan. Jakarta : Trans Info Media.

Mubarak. (2006). IImu Keperawatan Komunitas 2. Jakarta : Sagung Seto.

Notoatmodjo. (2010a). Metode Penelitian Kesehatan. Jakarta : Rineka Cipta

Notoatmodjo. (2010b). Promosi Kesehatan dan Aplikasi. Jakarta : Rineka Cipta

Pani. (2013). Pengaruh Penyuluhan Kelas Prenatal Plus Terhadap Pengetahuan dan Sikap Ibu Hamil di Wilayah Kerja Puskesmas Mamboro Kecamatan Palu Utara Kota Palu Provinsi Sulawesi Tengah. Available from : $<$ http://pasca.unhas.ac.id/jurnal/files/533c7718 7d305944329066432e78534a.pdf>. [Accesed : August 15, 2013].

Sarafino, E.P. (2006). Healt Psychology : Biopsychosocial Interactions. Fifth Edition. USA : John Wiley \& Son Schaffer, S. Graf 2000. Pencegahan Infeksi dan Praktek yang Aman. Jakarta: EGC

Sugiyono. (2007). Statistika untuk Penelitian. Bandung : Alfabeta.

Tirtarahardja dan Sulo. (2005). Pengantar Pendidikan. Jakarta : Rineka Cipta.

Undang-Undang Nomor 20 Tahun 2003 tentang Sistem Pendidikan Nasional

Waryono. (2010). Gizi Reproduksi. Yogyakarta : Pustaka Rihama.

Wawan dan Dewi. (2010). Pengetahuan, Sikap dan Perilaku Manusia. Yogjakarta : Nuha medika.

WHO. (2012). World Health Statistics 2012. WHO Library.

Wiknjosastro. (2008). Ilmu Kebidanan. Jakarta: Bina Pustaka Sarwono Prawirohardjo. 